Check for updates

Cite this: Phys. Chem. Chem. Phys., 2018, 20, 15002

Received 6th April 2018,

Accepted 4th May 2018

DOI: $10.1039 / c 8 c p 02187 b$

rsc.li/pccp

\section{Thermodynamics and defect chemistry of substitutional and interstitial cation doping in layered $\alpha-\mathrm{V}_{2} \mathrm{O}_{5} \dagger$}

\author{
Kit McColl, (D) Ian Johnson and Furio Corà*
}

\begin{abstract}
A systematic study of the location and energetics of cation dopants in $\alpha-\mathrm{V}_{2} \mathrm{O}_{5}$ has been conducted using pair-potential methods, supplemented by first-principles calculations. The consequences of doping on intrinsic defect equilibria have been discussed and the effects of selected dopants on $\mathrm{Li}^{+}$and $\mathrm{Mg}^{2+}$ diffusion energy barriers have been investigated.
\end{abstract}

The use of a metallic multivalent (MV) anode (i.e. $\mathrm{Mg}^{2+}, \mathrm{Ca}^{2+}$ or $\mathrm{Al}^{3+}$ ) represents a strategy to improve charge and energy density beyond present Li-ion battery technology. ${ }^{1} \mathrm{MV}$ ions introduce a charge multiplicity factor, and can also result in saving on space by avoiding the anode intercalation processes necessary for $\mathrm{Li}$. For example, $\mathrm{Mg}$ anodes do not exhibit the same dendritic growth issues upon cycling that plague Li-metal anodes, ${ }^{2}$ and thus metallic $\mathrm{Mg}$ can provide a far higher volumetric $(\mathrm{Mg}=$ $3833 \mathrm{~mA} \mathrm{~h} \mathrm{~cm}{ }^{-3}$ vs. $\mathrm{LiC}_{6}=800 \mathrm{~mA} \mathrm{~h} \mathrm{~cm}{ }^{-3}$ ) and gravimetric $\left(\mathrm{Mg}=2205 \mathrm{~mA} \mathrm{~h} \mathrm{~g}^{-1}\right.$ vs. $\left.\mathrm{LiC}_{6}=372 \mathrm{~mA} \mathrm{~h} \mathrm{~g}{ }^{-1}\right)$ capacity than intercalation anodes for $\mathrm{Li}^{3}$ A major challenge in the development of MV battery technologies is optimisation of cathode materials, many of which are currently limited by poor ion mobility, and show limited electrochemical performance. ${ }^{4}$ $\mathrm{V}_{2} \mathrm{O}_{5}$ was first investigated in the 1970's as a Li-ion intercalation cathode, but commercialization was never achieved, due to issues with cycling stability, electronic conductivity and Li-ion mobility. ${ }^{5}$ However interest has re-emerged as recent work has identified $\mathrm{V}_{2} \mathrm{O}_{5}$ as one of only a few materials which can reversibly intercalate $\mathrm{Mg}^{2+}$ ions, ${ }^{6}$ following discovery of the prototype MV cathode $\mathrm{Mg}_{x} \mathrm{Mo}_{3} \mathrm{~S}_{4} \cdot{ }^{7}$ Ion mobility and other issues have been partially overcome in $\mathrm{V}_{2} \mathrm{O}_{5}$ cathodes for Li-ion batteries through the introduction of dopants, many of which have offered improved electrochemical performance, ${ }^{8-15}$ and a summary of the figures of merit for doped $\mathrm{V}_{2} \mathrm{O}_{5}$ cathode materials can be found ref. 15. Such doping strategies may also be effective

Department of Chemistry, Christopher Ingold Building, University College London, 20 Gordon Street, London WC1H OAJ, UK. E-mail: f.cora@ucl.ac.uk

$\dagger$ Electronic supplementary information (ESI) available. See DOI: 10.1039/ c8cp02187b for $\mathrm{MV} \mathrm{V}_{2} \mathrm{O}_{5}$ cathodes. However a systematic evaluation of the likely location of dopants and the effects they have on $\mathrm{V}_{2} \mathrm{O}_{5}$ electrochemistry is thus far missing from the literature. Empirically-fitted pair potential methods have been demonstrated to provide insight into defect chemistry and ionic diffusion properties of battery materials. ${ }^{16}$ In this study we employ these methods, supplemented by first-principles calculations, to investigate the thermodynamics of cation doping in $\alpha-\mathrm{V}_{2} \mathrm{O}_{5}$, and the effect of these dopants on the mobility of $\mathrm{Li}^{+}$and $\mathrm{Mg}^{2+}$ ions.

The stable polymorph of $\mathrm{V}_{2} \mathrm{O}_{5}$ at ambient conditions is the orthorhombic $\alpha$-phase with space group Pmmn (no. 59) and lattice constants $a=3.564, b=11.512, c=4.368 \AA^{17}$ The layered structure is formed of distorted $\mathrm{VO}_{5}$ square pyramids, arranged sharing three corners and two edges with neighbouring pyramids (Fig. 1), with corner-sharing and edge

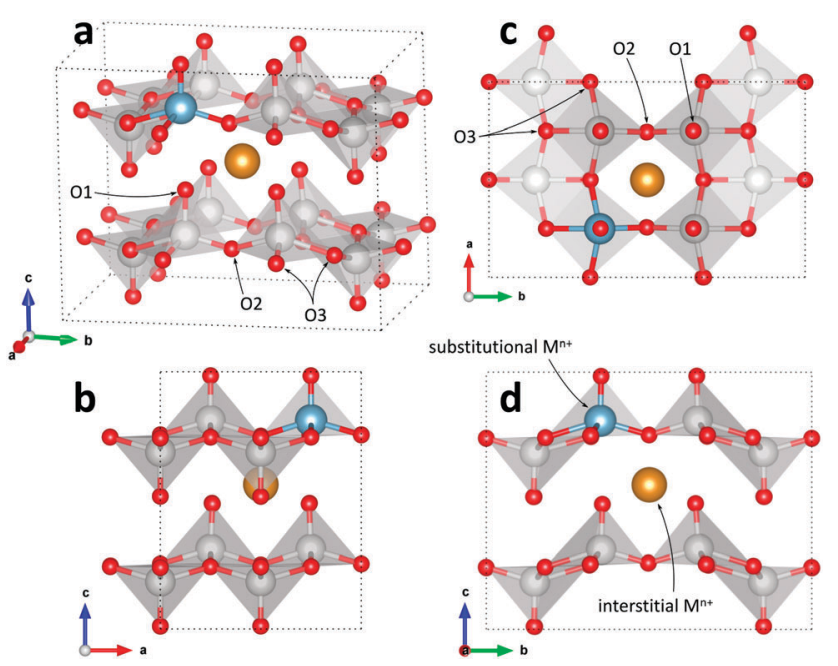

Fig. 1 Structure of $\alpha-\mathrm{V}_{2} \mathrm{O}_{5}(2 \times 1 \times 2$ expansion of the crystallographic unit cell) showing a 3D view (a), and projections along the [010] (b), [001] (c) and [100] (d) directions. Coloured spheres represent the following atoms; vanadium (grey), oxygen (red), substitutional dopants (blue) and interstitial dopants (gold). Shaded areas represent the $\mathrm{VO}_{5}$ square pyramidal coordination. 
sharing pairs oriented in opposite directions along the [001] axis. There are two $\mathrm{V}_{2} \mathrm{O}_{5}$ formula units in the crystallographic unit cell, which contains four symmetry unique atoms: one vanadium and three oxygen atoms, conventionally denoted $\mathrm{O}$, $\mathrm{O} 2$ and $\mathrm{O} 3,{ }^{18}$ with $\mathrm{O} 1$ corresponding to the oxygen at the end of the short $(1.585 \AA) \mathrm{V}-\mathrm{O} 1_{\text {vanadyl }}$ bond. Two-fold coordinate $\mathrm{O} 2$ atoms link between corner sharing $\mathrm{VO}_{5}$ pyramids in the [010] direction and three-fold coordinate $\mathrm{O} 3$ atoms link corner-sharing pyramids in the [100] direction. The interatomic $\mathrm{V}-\mathrm{O} 1_{\text {interlayer }}$ distance of $2.785 \AA$ is considered too long to be a conventional ionic or covalent interaction ${ }^{19}$ and the interlayer forces are therefore predominantly of a weak van der Waals (vdW) type.

$\mathrm{V}_{2} \mathrm{O}_{5}$ exhibiting conventional interlayer spacing (i.e. not of the aerogel or xerogel type $)^{20}$ can incorporate dopant cations into two possible sites: interstitial, residing between the $\mathrm{V}_{2} \mathrm{O}_{5}$ layers, or substitutional, replacing $\mathrm{V}^{5+}$ ions (Fig. 1). Steric effects can be expected to influence dopant location for ions of the same valence, however the predominant thermodynamic driving force determining the location of dopants of different valence is expected to be the energy of the associated defects that form to maintain overall charge neutrality in the lattice. Substitutional replacement of $\mathrm{V}^{5+}$ with cations of a lower charge will produce a net negative charge, which can be compensated by oxygen-ion vacancies, which have a net positive charge. Interstitial incorporation of dopants introduces a net positive charge to the lattice, which can be compensated either by interstitial oxygen-ions or vanadiumion vacancies, both of which bring a net negative charge to the lattice.

Initial investigations, considering a range of dopants with charge between +1 and +4 and all reasonable combinations of clustered and isolated cation and oxygen-ion defects, were conducted to determine the most stable charge compensation schemes for each dopant when incorporated into substitutional or interstitial sites. A full description of the calculations undertaken can be found in the ESI. $\uparrow$ The results indicate that when a substitutional cation with a lower charge than $\mathrm{V}^{5+}$ is accompanied by the formation of an oxygen-ion vacancy, the most stable arrangement is always as a clustered defect with the oxygen-ion vacancy at the short-bond $\mathrm{O} 1$ of the substitutional site. In other words, the $(\mathrm{VO})^{3+}$ vanadyl-like group behaves as a single unit and undergoes replacement as a whole. In the following, we consider this to be the predominant defect mechanism for substitutional $\mathrm{M}^{n+}$ dopants. Calculations (ESI $\dagger$ ) also determined that the prevalent charge balance for interstitial cations was by the formation of interstitial oxide ions, rather than the reduction of $\mathrm{V}$ to $\mathrm{V}^{4+}$ oxidation state, i.e. the localization of an electron on a $\mathrm{V}$ site to form a polaron, indicated as $\mathrm{V}_{\mathrm{V}}^{\prime}$ in Kröger-Vink $(\mathrm{K}-\mathrm{V})$ notation. $\mathrm{V}^{5+}$ or $(\mathrm{VO})^{3+}$ vacancies were never found to be stable relative to interstitial oxygen-ions as charge balance for interstitial $\mathrm{M}^{n+}$ dopants. Hereafter we present a series of defect formation equations in $\mathrm{K}-\mathrm{V}$ notation that represent the most stable schemes for incorporation of substitutional and interstitial $\mathrm{M}^{n+}$ ions $(n=1$, $2,3,4)$ into $\alpha-\mathrm{V}_{2} \mathrm{O}_{5}$.
$\mathrm{M}^{+}$ions:

$$
\begin{gathered}
\frac{1}{2} \mathrm{M}_{2} \mathrm{O} \rightarrow \mathrm{M}_{\mathrm{i}}^{\bullet}+\frac{1}{2} \mathrm{O}_{\mathrm{i}}^{\prime \prime} \\
\frac{1}{2} \mathrm{M}_{2} \mathrm{O}+\mathrm{VO}_{\mathrm{VO}}^{\times}+\mathrm{O}_{\mathrm{O}}^{\times} \rightarrow \mathrm{M}_{\mathrm{VO}}^{\prime \prime}+\square \ddot{\mathrm{O}}+\frac{1}{2} \mathrm{~V}_{2} \mathrm{O}_{5}
\end{gathered}
$$

$\mathrm{M}^{2+}$ ions:

$$
\begin{aligned}
& \mathrm{MO} \rightarrow \mathrm{M}_{\mathrm{i}}^{\bullet \bullet}+\mathrm{O}_{\mathrm{i}}^{\prime \prime} \\
& \mathrm{MO}+\mathrm{VO}_{\mathrm{VO}}^{\times}+\frac{1}{2} \mathrm{O}_{\mathrm{O}}^{\times} \rightarrow \mathrm{M}_{\mathrm{VO}}^{\prime}+\frac{1}{2} \square \stackrel{\mathrm{O}}{\bullet \bullet}+\frac{1}{2} \mathrm{~V}_{2} \mathrm{O}_{5}
\end{aligned}
$$

$\mathrm{M}^{3+}$ ions:

$$
\begin{gathered}
\frac{1}{2} \mathrm{M}_{2} \mathrm{O}_{3} \rightarrow \mathrm{M}_{\mathrm{i}}^{\bullet \bullet \bullet}+\frac{3}{2} \mathrm{O}_{\mathrm{i}}^{\prime \prime} \\
\frac{1}{2} \mathrm{M}_{2} \mathrm{O}_{3}+\mathrm{VO}_{\mathrm{VO}}^{\times} \rightarrow \mathrm{M}_{\mathrm{VO}}^{\times}+\frac{1}{2} \mathrm{~V}_{2} \mathrm{O}_{5}
\end{gathered}
$$

$\mathrm{M}^{4+}$ ions:

$$
\begin{gathered}
\mathrm{MO}_{2} \rightarrow \mathrm{M}_{\mathrm{i}}^{\bullet \bullet \bullet}+2 \mathrm{O}_{\mathrm{i}}^{\prime \prime} \\
\mathrm{MO}_{2}+\mathrm{VO}_{\mathrm{VO}}^{\times}+\mathrm{V}_{\mathrm{V}}^{\prime}+\frac{1}{2} \square \stackrel{\mathrm{O}}{\bullet} \rightarrow \mathrm{M}_{\mathrm{VO}}^{\bullet}+\mathrm{V}_{\mathrm{V}}^{\prime}+\frac{1}{2} \mathrm{~V}_{2} \mathrm{O}_{5}
\end{gathered}
$$

Implications for $\mathbf{M}^{5+}$ and $\mathbf{M}^{6+}$ dopants will be discussed later.

The calculated reaction energies for the schemes detailed above, conducted for a range of $28 \mathrm{M}^{n+}$ ions listed in the ESI, $\dagger$ are reported in Fig. 2, plotted as a function of ionic radii. The results indicate that the interstitial sites for all $\mathbf{M}^{+}$(red) and $\mathbf{M}^{2+}$ ions (gold) are more stable than substitutional incorporation, the difference being $\sim 6 \mathrm{eV}$ for $\mathrm{M}^{+}$and $\sim 4 \mathrm{eV}$ for $\mathrm{M}^{2+}$ ions. Our calculations therefore suggest that $\mathrm{M}^{+}$and $\mathrm{M}^{2+}$ ions will only be incorporated interstitially, regardless of their ionic radius. The $\mathrm{M}^{+}$and $\mathrm{M}^{2+}$ interstitial sites are most stable at an ionic radius of $\sim 1 \AA$, which indicates that the $\mathrm{V}_{2} \mathrm{O}_{5}$ structure is suited to accommodate ion of this size within the interlayer space.

The $\mathrm{M}^{3+}$ interstitial defects become more stable as the ionic radius of the dopant increases. The larger variation in energy as a function of ionic radius for the $\mathrm{M}^{3+}$ ions compared to the $\mathrm{M}^{+}$ and $\mathrm{M}^{2+}$ ions indicates that the higher charge of the $\mathrm{M}^{3+}$ ions creates a greater distortion of the lattice around the dopant, and this distortion is more pronounced when the ions are smaller. The reaction energy of the substitutional $\mathbf{M}^{3+}$ defects are close in energy to the $\mathbf{M}^{3+}$ interstitial defects. The reaction energy increases less quickly as a function of decreasing $\mathbf{M}^{3+}$ ionic radius for substitutional rather than for the interstitial defects, and thus the most stable site for $\mathbf{M}^{3+}$ defects swaps from substitutional to interstitial as ionic radius increases. The calculations suggest that for $\mathbf{M}^{3+}$ ions whose ionic radius is greater than $\sim 0.7 \AA$, interstitial sites are more stable, whereas ions smaller than this are more stable in substitutional sites. Consequently, both substitutional and interstitial defects may be possible for $\mathrm{M}^{3+}$ ions, and the location of the dopant may be tailored by the use of kinetic or thermodynamic control during synthesis and post-processing. For $\mathrm{M}^{4+}$ ions, substitutional 


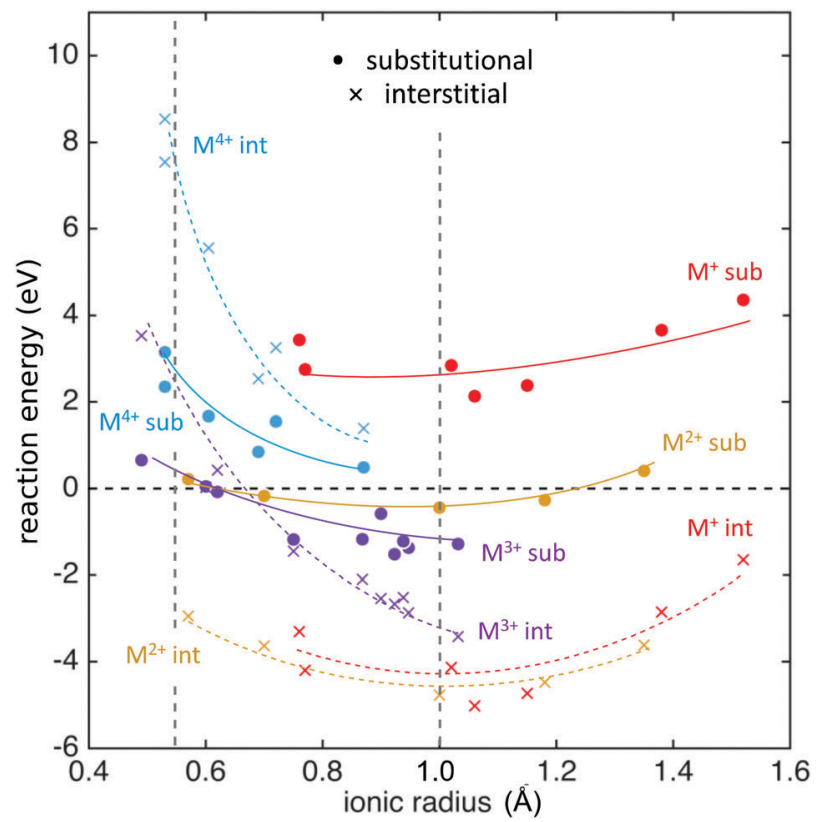

Fig. 2 Reaction energy energies for $\mathrm{M}^{n+}$ cations (ESI $\dagger$ ) as a function of dopant ionic radius. Circles indicate substitutional defects, and crosses indicate interstitial defects. Different dopant cation valences are indicated by the differently colored markers. Approximate trends in cation series of the same valence are indicated by the solid and dotted coloured lines, which are intended as guides for the eye only. A dashed vertical line at $0.54 \AA$ indicates the ionic radius of $\mathrm{V}^{5+}$. The dashed vertical line at $1.0 \AA$ indicates the approximate minimum reaction energy for substitutional ions, and is an estimate for the effective ionic radius of the vanadyl ion.

sites are more stable than interstitial sites for all ionic radii, with a much greater difference in energy for smaller ions, which will only occupy substitutional sites. There is a narrowing of the energy difference between substitutional and interstitial sites for larger $\mathrm{M}^{4+}$ ions. The calculations therefore suggest that large interstitial $\mathrm{M}^{4+}$ doped $\mathrm{V}_{2} \mathrm{O}_{5}$ may be a metastable product accessible under some kinetically controlled synthesis conditions. A correlation between substitutional dopant ionic radius and reaction energy has been observed for several solids, including perovskites, and it usually yields lowest energy when the ionic radius of the dopant and the host crystal ion it replaces are similar. ${ }^{21}$ This is not the case here, since we find that $\mathrm{M}^{n+}$ dopants $(n<5)$ replace $\left(\mathrm{VO}^{3+}\right)$ ions as a whole, rather than $\mathrm{V}^{5+}$ ions. The position of the minimum reaction energy, which is found at an ionic radius of $\sim 1.0 \AA$ for substitutional dopants of all net charges, suggests this is an estimate for the effective radius of the vanadyl ion.

Whilst these atomistic simulation methods have been applied successfully to investigate dopants in battery materials previously, ${ }^{16,22}$ their empirical nature and the challenges of representing a complex layered structure like $\mathrm{V}_{2} \mathrm{O}_{5}$ using fitted potentials mean that the values of reaction energies will be subject to some error, the magnitude of which is challenging to evaluate accurately. Any errors present will be particularly important for the predictions of thermodynamic stability of $\mathrm{M}^{3+}$ ions, and large $\mathrm{M}^{4+}$ where the substitutional and interstitial sites are similar in energy. As a test of their reliability, we have compared the pair-potential results with calculations performed using density functional theory (DFT), investigating substitutional $\mathrm{Al}^{3+}$ and $\mathrm{Fe}^{3+}$ incorporation (ESI $\dagger$ ). The results show good agreement between the techniques, and reproduction of the pair-potential results using quantum-mechanics supports their validity.

The location of dopants in $\mathrm{V}_{2} \mathrm{O}_{5}$ and the defects that form to compensate the dopant charge, influence the concentration of $\mathrm{V}^{4+}$ and oxygen vacancies in the material, which in turn are expected to affect the electrochemical performance. ${ }^{23,24}$ As with many early transition metal oxides, $\mathrm{V}_{2} \mathrm{O}_{5}$ is typically an oxygendeficient intrinsic n-type semiconductor ${ }^{25}$ (and may therefore more accurately denoted as $\mathrm{V}_{2} \mathrm{O}_{5-\delta}$ ), often due to a combination of incomplete oxidation of the vanadium ions in the precursor and facile oxygen vacancy formation in the bulk material. Intrinsic oxygen deficiency is charge compensated in the structure of $\mathrm{V}_{2} \mathrm{O}_{5}$ by the presence of a measurable concentration of $\mathrm{V}^{4+}$ ions, whose $\mathrm{d}^{1}$ electrons $\left(\mathrm{V}_{\mathrm{V}}^{\prime}\right)$ are associated with increased electronic conductivity. ${ }^{26}$ The formation of oxygen vacancies and $\mathrm{V}^{4+}$ in $\mathrm{V}_{2} \mathrm{O}_{5}$ can be represented, in Kröger-Vink notation as:

$$
2 \mathrm{~V}_{\mathrm{V}}^{\times}+\mathrm{O}_{\mathrm{O}}^{\times} \leftrightharpoons 2 \mathrm{~V}_{\mathrm{V}}^{\prime}+\square_{\mathrm{O}}^{\ddot{*}}+\frac{1}{2} \mathrm{O}_{2}
$$

The chemical equilibrium that governs the formation of oxygen vacancies and polarons, will be represented by an equilibrium reaction constant $K_{\text {eq }}$, expressed by the mass law:

$$
K_{\mathrm{eq}}=[\square \stackrel{\bullet}{\bullet}]\left[\mathrm{V}_{\mathrm{V}}^{\prime}\right]^{2} \cdot p \mathrm{O}^{\frac{1}{2}}
$$

where the intrinsic concentration of oxygen vacancies is approximately equivalent to half the concentration of $\mathrm{V}^{4+}$ :

$$
[\square \ddot{\mathrm{O}}] \approx \frac{1}{2}\left[\mathrm{~V}_{\mathrm{V}}^{\prime}\right]
$$

The formation of intrinsic oxygen Frenkel defects are also relevant to the defect equilibria and can be expressed as:

$$
\mathrm{O}_{\mathrm{O}}^{\times} \leftrightharpoons \mathrm{O}_{\mathrm{i}}^{\prime \prime}+\square \ddot{\mathrm{O}}
$$

O-Frenkel defect formation will have a low equilibrium constant in $\mathrm{V}_{2} \mathrm{O}_{5}$, due to the tendency for oxygen deficiency:

$$
K_{\mathrm{O}-\text { Frenkel }}=\left[\square{ }_{\mathrm{O}}^{\bullet \bullet}\right]\left[\mathrm{O}_{\mathrm{i}}^{\prime \prime}\right]
$$

thus the concentration of oxygen vacancies exceeds the concentration of oxide interstitials:

$$
[\square \cdot \bullet] \gg\left[\mathrm{O}_{\mathrm{i}}^{\prime \prime}\right]
$$

Calculations discussed earlier indicate that $\mathrm{M}^{+}, \mathrm{M}^{2+}$ and large $\mathrm{M}^{3+}$ ions are expected to be incorporated interstitially, along with interstitial oxygen-ions. The tendency for oxygen deficiency and the accessible redox of $\mathrm{V}^{5+} / \mathrm{V}^{4+}$ in the lattice means that rather than residing in the structure, extrinsic interstitial oxygen-ions will anneal out some of the intrinsic oxygen vacancies:

$$
\mathrm{M}_{\mathrm{i}}^{\bullet \bullet}+\mathrm{O}_{\mathrm{i}}^{\prime \prime}+2 \mathrm{~V}_{\mathrm{V}}^{\prime}+\square_{\mathrm{O}}^{\bullet} \rightarrow \mathrm{M}_{\mathrm{i}}^{\bullet \bullet}+2 \mathrm{~V}_{\mathrm{V}}^{\prime}
$$

Thus the introduction of interstitial $\mathrm{M}^{+}, \mathrm{M}^{2+}$ and $\mathrm{M}^{3+}$ ions into $\mathrm{V}_{2} \mathrm{O}_{5}$ will tend to increase the concentration of $\mathrm{V}^{4+}$ ions, or 
increase the ratio of $\mathrm{V}^{4+}$ ions to oxygen vacancies. This mechanism is likely to improve electronic conductivity and may account for the enhanced electrochemical performance for a range of $\mathrm{M}^{+}, \mathrm{M}^{2+}$ and $\mathrm{M}^{3+}$ doped $\mathrm{V}_{2} \mathrm{O}_{5}$ battery cathodes. ${ }^{8-12} \mathrm{M}^{3+}$ ions, when incorporated into substitutional sites, generate oxygen vacancies for charge balance. In oxygen-deficient $\mathrm{V}_{2} \mathrm{O}_{5}$, the generation of excess extrinsic oxygen vacancies shifts the equilibrium of eqn (ix) towards $\mathrm{V}^{5+}$, and thus anneals out $\mathrm{V}^{4+}$. Substitutional doping with $\mathrm{M}^{3+}$ ions may therefore result in poorer electronic conductivity and degraded electrochemical performance of $\mathrm{V}_{2} \mathrm{O}_{5}$ due to the lower concentration or charge carrying $\mathrm{d}^{1}$ electrons on $\mathrm{V}^{4+}$ ions. The mechanism for the substitutional incorporation of $\mathrm{M}^{4+}$ ions, i.e. the replacement of a vanadyl (VO) ${ }^{3+}$ group with $\mathrm{M}^{4+}$ (eqn (viii)) will leave a net charge of +1 for each dopant introduced, charge balanced by $\mathrm{V}^{4+}$. This effectively constitutes annealing out of oxygen-ion vacancies, and will result in an increased concentration of $\mathrm{d}^{1}$ electrons that are not bound to oxygen-ion vacancies in a polaron-pair. This process is likely to contribute to enhanced electronic conductivity and the improved electrochemical performance of $\mathrm{M}^{4+}$ doped $\mathrm{V}_{2} \mathrm{O}_{5}$ systems. ${ }^{13,14,27,28}$

Due to the limitations of the available potential models, no atomistic defect formation calculations were performed for $\mathrm{M}^{5+}$ or $\mathrm{M}^{6+}$ ions. We can however infer from the trends in the $\mathrm{M}^{+}$to $\mathrm{M}^{4+}$ series, that both $\mathrm{M}^{5+}$ and $\mathrm{M}^{6+}$ ions will prefer to be incorporated substitutionally rather than interstitially regardless of their size. $\mathrm{M}^{5+}$ ions will not require charge balancing upon incorporation, and are therefore not expected to significantly modify the concentration of $\mathrm{V}^{4+}$ and oxygen vacancies relative to pristine $\mathrm{V}_{2} \mathrm{O}_{5}$. $\mathrm{M}^{6+}$ ions are likely to substitute and either anneal out oxygen-ion vacancies, or introduce interstitial oxygen ions:

$$
\begin{gathered}
\mathrm{MO}_{3}+\mathrm{V}_{\mathrm{V}}^{\times}+\frac{1}{2} \square \ddot{\mathrm{O}} \rightarrow \mathrm{M}_{\mathrm{V}}^{\bullet}+\frac{1}{2} \mathrm{~V}_{2} \mathrm{O}_{5} \\
\mathrm{MO}_{3}+\mathrm{V}_{\mathrm{V}}^{\times} \rightarrow \mathrm{M}_{\mathrm{V}}^{\bullet}+\frac{1}{2} \mathrm{O}_{\mathrm{i}}^{\prime \prime}+\frac{1}{2} \mathrm{~V}_{2} \mathrm{O}_{5}
\end{gathered}
$$

Both mechanisms are expected to result in a higher concentration of $\mathrm{V}^{4+}$ ions, or a higher ratio of $\mathrm{V}^{4+}$ to oxygen vacancies.

The location of dopants in $\mathrm{V}_{2} \mathrm{O}_{5}$ will have an influence on the mobility of ions through the structure. Possible effects include modifying the interlayer separation, ${ }^{13}$ blocking diffusion channels, ${ }^{29}$ introducing additional Coulombic interactions between intercalants and dopants ions and providing sites for nucleation and growth of different phases during cycling. ${ }^{30}$ Dopants may also be expected to alter the extent and effect of local polaronic distortions, which have been demonstrated to produce lithiation gradients and inhibit $\mathrm{Li}^{+}$mobility in $\mathrm{V}_{2} \mathrm{O}_{5}$ nanowires. ${ }^{31}$ Here we consider the effects of interstitial $\mathrm{Na}^{+}$and $\mathrm{Ba}^{2+}$, and substitutional $\mathrm{Al}^{3+}$ dopants on the energy barriers for $\mathrm{Li}^{+}$and $\mathrm{Mg}^{2+}$ diffusion in the [100] direction of $\alpha-\mathrm{V}_{2} \mathrm{O}_{5}$. The diffusion pathways relative to the dopants are indicated on Fig. $3 \mathrm{a}$ and $\mathrm{b}$, and the energy barriers in Fig. $3 \mathrm{c}$ and $\mathrm{d}$.

For the Al doped phase, formation of a $\mathrm{Al}_{\mathrm{vO}}^{\times}$defect removes one $\mathrm{O} 1$ from the interlayer space, below Al (Fig. 3b). Pathway 1 indicates $\mathrm{Li}^{+} / \mathrm{Mg}^{2+}$ migration through the O-vacancy, whilst pathway 2 relates to migration through the layer above $\mathrm{Al}$, where the $\mathrm{O} 1$ ion is
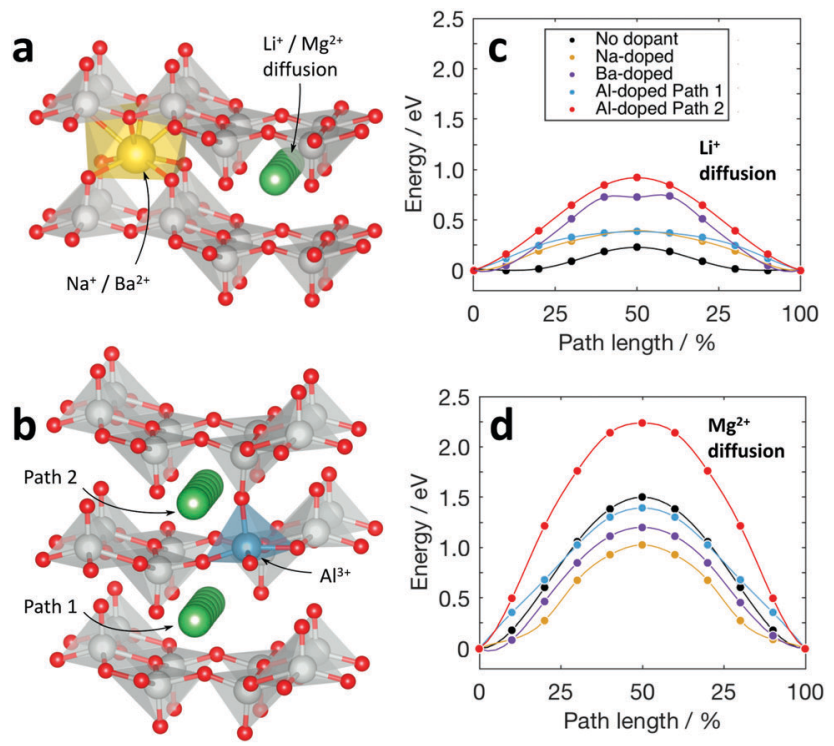

Fig. 3 Diffusion pathways for $\mathrm{Li}^{+}$and $\mathrm{Mg}^{2+}$ relative to the selected dopants (a) interstitial $\mathrm{Na}^{+}$and $\mathrm{Ba}^{2+}$, and (b) substitutional $\mathrm{Al}^{3+}$. (c and d) Show the energy barriers for $\mathrm{Li}^{+}$and $\mathrm{Mg}^{2+}$ diffusion respectively.

more tightly bound to the two adjacent layers. In undoped $\mathrm{V}_{2} \mathrm{O}$, the barrier for $\mathrm{Li}^{+}$diffusion $(0.23 \mathrm{eV})$ is significantly lower than for $\mathrm{Mg}^{2+}$ $(1.51 \mathrm{eV})$, consistent with first-principles calculations. ${ }^{3,32} \mathrm{For} \mathrm{Li}^{+}$ diffusion, all the selected dopants cause an increase in energy barrier, indicating that any distortion along the diffusion pathway induced by a dopant can hinder ion mobility. Electrostatic interactions between the dopants and diffusing ions also contribute to the increased energy barriers. For $\mathrm{Mg}^{2+}$ diffusion, the $\mathrm{Al}^{3+}$ substituted system displays an increased energy barrier for path 2 $(2.23 \mathrm{eV})$, but a reduced barrier for path $1(1.4 \mathrm{eV})$. Despite the barrier reduction, an energy of $1.4 \mathrm{eV}$ effectively renders diffusion unachievable at room temperature. The interstitially doped structures have energy barriers of $1.02 \mathrm{eV}\left(\mathrm{Na}_{\mathrm{int}}{ }^{+}\right)$and $1.20 \mathrm{eV}\left(\mathrm{Ba}_{\mathrm{int}}{ }^{2+}\right)$, a substantial reduction from $1.61 \mathrm{eV}$ for the undoped system. The lower energy barriers can be explained by an expansion of the interlayer space upon introduction of the dopant, which shifts the relative energy of the 8-coordinated stable insertion site and 3-coordinated barrier site closer together. ${ }^{33} \mathrm{Ba}^{2+}$ is larger than $\mathrm{Na}^{+}$and causes a greater interlayer expansion, yet $\mathrm{Ba}^{2+}$ doping results in a higher energy barrier than $\mathrm{Na}^{+}$doping for $\mathrm{Mg}^{2+}$ diffusion, suggesting that there is an optimal expansion to the interlayer space that will minimize the diffusion energy barrier, and that this may be achieved by tailoring the dopant concentration and size. The results of these diffusion barrier calculations can be used as a guide for future, more detailed investigation of dopant effects on ion diffusion, using quantum-mechanical techniques.

The authors acknowledge funding from the EPSRC through grant EP/R023662/1 and the use of the UCL Grace and Legion High Performance Computing Facilities (Grace@UCL, Legion@UCL), and associated support services. Via our membership of the UK's HEC Materials Chemistry Consortium, which is funded by the EPSRC (EP/L000202), this work used the ARCHER UK National Supercomputing Service (http://www.archer.ac.uk). 


\section{Conflicts of interest}

There are no conflicts to declare.

\section{References}

1 P. Canepa, G. Sai Gautam, D. C. Hannah, R. Malik, M. Liu, K. G. Gallagher, K. A. Persson and G. Ceder, Chem. Rev., 2017, 117, 4287-4341.

2 W. Xu, J. Wang, F. Ding, X. Chen, E. Nasybulin, Y. Zhang and J.-G. Zhang, Energy Environ. Sci., 2014, 7, 513-537.

3 G. S. Gautam, P. Canepa, R. Malik, M. Liu, K. Persson and G. Ceder, Chem. Commun., 2015, 51, 13619-13622.

4 H. D. Yoo, I. Shterenberg, Y. Gofer, G. Gershinsky, N. Pour and D. Aurbach, Energy Environ. Sci., 2013, 6, 2265-2279.

5 M. S. Whittingham, Chem. Rev., 2004, 104, 4271-4301.

6 G. G. Amatucci, F. Badway, A. Singhal, B. Beaudoin, G. Skandan, T. Bowmer, I. Plitz, N. Pereira, T. Chapman and R. Jaworski, J. Electrochem. Soc., 2001, 148, A940-A950.

7 D. Aurbach, Z. Lu, A. Schechter, Y. Gofer, H. Gizbar, R. Turgeman, Y. Cohen, M. Moshkovich and E. Levi, Nature, 2000, 407, 724-727.

8 Y.-Z. Zheng, H. Ding, E. Uchaker, X. Tao, J.-F. Chen, Q. Zhang and G. Cao, J. Mater. Chem. A, 2015, 3, 1979-1985.

9 F. Coustier, J. Hill, B. B. Owens, S. Passerini and W. H. Smyrl, J. Electrochem. Soc., 1999, 146, 1355-1360.

10 H. Zeng, D. Liu, Y. Zhang, K. A. See, Y. S. Jun, G. Wu, J. A. Gerbec, X. Ji and G. D. Stucky, Chem. Mater., 2015, 27, 7331-7336.

11 X. Li, C. Liu, C. Zhang, H. Fu, X. Nan, W. Ma, Z. Li, K. Wang, H. Wu and G. Cao, ACS Appl. Mater. Interfaces, 2016, 8, 24629-24637.

12 Y. Wei, C. W. Ryu and K. B. Kim, J. Alloys Compd., 2008, 459, 13-17.

13 Z. Li, C. Zhang, C. Liu, H. Fu, X. Nan, K. Wang, X. Li, W. Ma, X. Lu and G. Cao, Electrochim. Acta, 2016, 222, 1831-1838.

14 Y. Li, J. Yao, E. Uchaker, M. Zhang, J. Tian, X. Liu and G. Cao, J. Phys. Chem. C, 2013, 117, 23507-23514.

15 X. Liu, J. Zeng, H. Yang, K. Zhou and D. Pan, RSC Adv., 2018, 8, 4014-4031.
16 M. S. Islam and C. A. J. Fisher, Chem. Soc. Rev., 2014, 43, 185-204.

17 R. Enjalbert and J. Galy, Acta Crystallogr., 1986, C42, 1467-1469.

18 D. O. Scanlon, A. Walsh, B. J. Morgan and G. W. Watson, J. Phys. Chem. C, 2008, 112, 9903-9911.

19 V. Riffet, J. Contreras-Garclá, J. Carrasco and M. Calatayud, J. Phys. Chem. C, 2016, 120, 4259-4265.

20 M. Giorgetti, M. Berrettoni and W. H. Smyrl, Chem. Mater., 2007, 19, 5991-6000.

21 M. S. Islam, J. Mater. Chem., 2000, 10, 1027-1038.

22 J. S. Braithwaite, C. R. A. Catlow, J. D. Gale and J. H. Harding, Chem. Mater., 1999, 11, 1990-1998.

23 Y. L. Cheah, V. Aravindan and S. Madhavi, ACS Appl. Mater. Interfaces, 2012, 4, 3270-3277.

24 X. Liang, G. Gao, Y. Liu, T. Zhang and G. Wu, J. Alloys Compd., 2017, 715, 374-383.

25 T. Allersma, R. Hakim, T. N. Kennedy and J. D. Mackenzie, J. Chem. Phys., 1967, 46, 154-160.

26 I. B. Ioffe and V. A. Patrina, Phys. Status Solidi, 1970, 389, 389-395.

27 M. B. Sahana, C. Sudakar, C. Thapa, V. M. Naik, G. W. Auner, R. Naik and K. R. Padmanabhan, Thin Solid Films, 2009, 517, 6642-6651.

28 C. F. Armer, M. Lübke, M. V. Reddy, J. A. Darr, X. Li and A. Lowe, J. Power Sources, 2017, 353, 40-50.

29 M. Panagopoulou, D. Vernardou, E. Koudoumas, N. Katsarakis, D. Tsoukalas and Y. S. Raptis, J. Phys. Chem. C, 2017, 121, 70-79.

30 D. M. Yu, S. T. Zhang, D. W. Liu, X. Y. Zhou, S. H. Xie, Q. F. Zhang, Y. Y. Liu and G. Z. Cao, J. Mater. Chem., 2010, 20, 10841-10846.

31 L. R. De Jesus, G. A. Horrocks, Y. Liang, A. Parija, C. Jaye, L. Wangoh, J. Wang, D. A. Fischer, L. F. J. Piper, D. Prendergast and S. Banerjee, Nat. Commun., 2016, 7, 12022.

32 A. Parija, Y. Liang, J. L. Andrews, L. R. De Jesus, D. Prendergast and S. Banerjee, Chem. Mater., 2016, 28, 5611-5620.

33 Z. Rong, R. Malik, P. Canepa, G. Sai Gautam, M. Liu, A. Jain, K. Persson and G. Ceder, Chem. Mater., 2015, 27, 6016-6021. 